\title{
ANALISIS DAYA HIDUP DAN PERTUMBUHAN BENIH BIJI MARGA Shorea ROXB. EX C.F.GAERTN. DI PERSEMAIAN
}

\section{(Analysis of Germination and Growth Rate from Seed of Shorea Roxb. ex C.F.Gaertn. in Nursery)}

\author{
Nurul Ihsan Fawzi dan Juliansyah \\ Yayasan Alam Sehat Lestari \\ Sukadana, Kalimantan Barat, 78852 Indonesia \\ e-mail:nurul.ihsan.f@mail.ugm.ac.id
}

Diterima: 25 November 2019, Direvisi: 27 November 2019, Disetujui: 31 Desember 2019

DOI: https://doi.org/10.31849/forestra

\begin{abstract}
Deforestation in Kalimantan island made 17 million hectares of primary forest loss in the last 40 years. The forest restoration project needs native species seedlings from the previous tree on the damaged forest. The aim of this study to determine the germination and growth of the types of Shorea obtained from TNGP. This study used 38,728 seeds from four species of the Shorea genus: red meranti (Shorea leprosula), Tengkawang (Shorea macrophylla), white meranti (Shorea agami), and belabak (Shorea quadrinervis) obtained from forests near reforestation sites. The result show the average germination rate is $80 \%$. The highest germination rate from the Shorea quadrinervis is 98.7\%. We found that the growth of the Shorea genus from seeds is ready for planting in a period of 4 - 5 months.
\end{abstract}

Keyword: Shorea, germination rate, growth rate, Gunung Palung

\begin{abstract}
ABSTRAK
Deforestasi di Pulau Kalimantan telah menyebabkan 17 juta hektar hutan primer hilang selama 40 tahun terakhir. Untuk program reboisasi tersebut dibutuhkan bibit-bibit spesies native dari spesiesspesies sebelumnya yang tumbuh. Tujuan penelitian ini adalah untuk mengetahui perkebangan perkecambahan dan pertumbuhan dari jenis-jenis Shorea yang diperoleh dari TNGP. Penelitian ini menggunakan 38.728 benih dari biji dari empat spesies dari marga Shorea: meranti merah (Shorea leprosula), tengkawang (Shorea macrophylla), meranti putih (Shorea agami), dan belabak (Shorea quadrinervis) yang diperoleh dari hutan disekitar lokasi reboisasi. Hasilnya daya benih dari biji untuk 4 spesies dari marga Shorea berada diatas $80 \%$. Daya hidup perkecambahan paling tinggi pada Shorea quadrinervis sebesar 98,7\%. Kami temukan bahwa pertumbuhan marga Shorea dari biji telah siap tanam dalam periode $4-5$ bulan.
\end{abstract}

Kata kunci : Shorea, daya hidup biji, pertumbuhan bibit, Gunung Palung 


\section{PENDAhuluan}

Deforestasi di Pulau Kalimantan telah menyebabkan hampir 17 juta hektar hutan primer hilang selama 40 tahun terakhir (Gaveau et al., 2014). Penyebab utama dari deforestasi ini adalah konversi untuk perkebunan kelapa sawit dan kebakaran lahan yang dipicu oleh El Niño (Gaveau et al., 2019; Sloan et al., 2017). Dampak deforestasi menyebabkan hutan berubah menjadi lahan terbuka atau padang rumput yang meningkatkan erosi tanah, emisi karbon, banjir, dan perubahan iklim. Deforestasi juga terjadi di kawasan lindung, terutama akibat illegal logging dan aktivitas pertanian (Curran et al., 2004).

Taman Nasional Gunung Palung (TNGP) merupakan salah satu kawasan hutan yang mengalami deforestasi dan kehilangan $30 \%$ hutan primernya dalam 30 tahun terakhir (Curran et al., 2004; Fawzi et al., 2019). Penyebab deforestasi utama di TNGP adalah akibat dari aktivitas pembalakan liar (illegal logging) dan konversi menjadi lahan pertanian (Zamzani et al., 2009). Sebanyak 26\% hutan primer yang hilang tersebut telah kembali menjadi hutan sekunder melalui regenerasi alami.
Sembilan persen area yang tersisa, sebanyak 5.000 Ha (5\%) merupakan padang rumput (didominasi oleh Imperata grassland dan Scleria sumatrensis) dan sisanya (4\%) merupakan kawasan taman nasional yang dimanfaatkan masyarakat untuk berkebun atau berladang. Untuk bertani padi (sawah), mereka tidak memanfaatkan lahan taman nasional karena membutuhkan area yang landai untuk membuat sawah (Salafsky, 1994).

Upaya konservasi untuk mengurangi laju deforestasi telah berhasil dalam 10 tahun terakhir. Permasalahan yang muncul berikutnya adalah bagaimana mengembalikan kondisi ekosistem hutan yang telah rusak kembali seperti sedia kala. Mengatasi masalah deforestasi yang terjadi harus diimbangi dengan restorasi hutan untuk mensekuestrasi karbon di atmofer (Crowther et al., 2017). Istilah restorasi hutan adalah kata lain dari reboisasi, rehabilitasi, atau penghijauan (Elliott et al., 2013). Definisi teknisnya adalah menanam pohon pada area hutan yang telah rusak untuk mengembalikan fungsi ekosistem seperti semula. Pada area TN. Gunung Palung yang rusak menjadi padang rumput, restorasi hutan telah berdampak positif 
terhadap ekosistem dan persepsi sosial masyarakat terhadap konservasi (Helms et al., 2018; Pohnan et al., 2015). Untuk program reboisasi tersebut dibutuhkan bibit-bibit spesies native dari spesiesspesies sebelumnya yang tumbuh. Dalam Rencana Pemulihan Ekosistem TNGP 2018 - 2023, masih terdapat 4,882 hektar areal terdeforestasi yang membutuhkan upaya reboisasi. Untuk itu dibutuhkan penyiapan bibit dengan kualitas yang bagus.

Kebutuhan penyediaan bibit dengan kualitas bagus ini berkontribusi terhadap kesuksesan program reboisasi. Pada areaarea hutan yang telah rusak yang ditumbuhi oleh alang-alang (Imperata cylindrica), tidak memungkinkan regenerasi alami karena benih dari biji dapat hidup akibat kalah kompetisi alami. Penyediaan bibitbibit native di TNGP membutuhkan informasi tentang daya hidup dan pertumbuhan benih untuk membuat perencanaan reboisasi yang tepat. TNGP merupakan habitat terbesar dari suku Dipterocarpaceae di Indonesia. Marga Shorea Roxb. ex C.F.Gaertn. adalah salah satu spesies native yang harus prioritas utama dalam upaya reboisasi. Marga shorea atau lebih dikenal dengan jenis meranti adalah jenis kayu yang paling banyak dicari dalam pembalakan liar (Wadley, 2006).

Informasi tentang perkecambahan dan daya hidup benih dari biji (survival rate) masih terbatas untuk marga Shorea. Beberapa penelitian sebelumnya yang telah dilakukan, menemukan bahwa Shorea parvifolia memiliki tingkat perkecambahan paling tinggi sebesar 85\% (Otsamo et al., 1996). Jenis lainnya memiliki tingkat perkecambahan yang rendah karena kualitas bibit yang buruk. Ketika musim kemarau panjang yang dipengaruhi oleh El Nino, Shorea berbunga dari bulan Agustus hingga Oktober, dan berbuah di bulan Januari hingga Maret (Curran and Leighton, 2000). Pada masa tersebut adalah kondisi tepat untuk mengumpulkan benih dari biji dan membibitkannya. Tujuan penelitian ini adalah (1) untuk mengetahui perkebangan perkecambahan dari biji Shorea dan (2) pertumbuhan dari jenis-jenis Shorea yang diperoleh dari TNGP. Tujuan ini merupakan salah satu upaya reboisasi yang dilakukan di TNGP sejak tahun 2009. 


\section{METODE PENELITIAN}

\section{A. Lokasi Penelitian}

Penelitian dilakukan di persemaian reboisasi Yayasan Alam Sehat Lestari (ASRI) di Desa Laman Satong Km. 20, Kabupaten Ketapang, Kalimantan Barat (Gambar 1). Lokasi a di Desa Laman Satong Km. $20 \quad\left(1^{\circ} 22^{\prime} 06.2^{\prime \prime} \quad\right.$ LS $\left.110^{\circ} 13^{\prime} 25.2^{\prime \prime} \mathrm{BT}\right)$ merupakan hutan tropis dataran rendah yang rusak akibat illegal logging dan aktivitas perusahaan kayu PT. Marsela Wana Sekawan di tahun 1997 -
2002 (Ode, 2012). Hutan yang telah ditebang tidak mampu untuk regenerasi alami, sehingga ditumbuhi oleh paku resam (Pteredium aquilinum) dan alangalang (Imperata cylindrica) yang selalu terbakar setiap tahun. Di lokasi ini tidak ada aktivitas masyarakat untuk bertani, sehingga restorasi hutan murni untuk pengembalian ekosistem hutan. Hingga akhir tahun 2018, telah direstorasi 30 hektar dengan metode tanam sistem kerapatan tinggi (3.100 bibit/hektar).

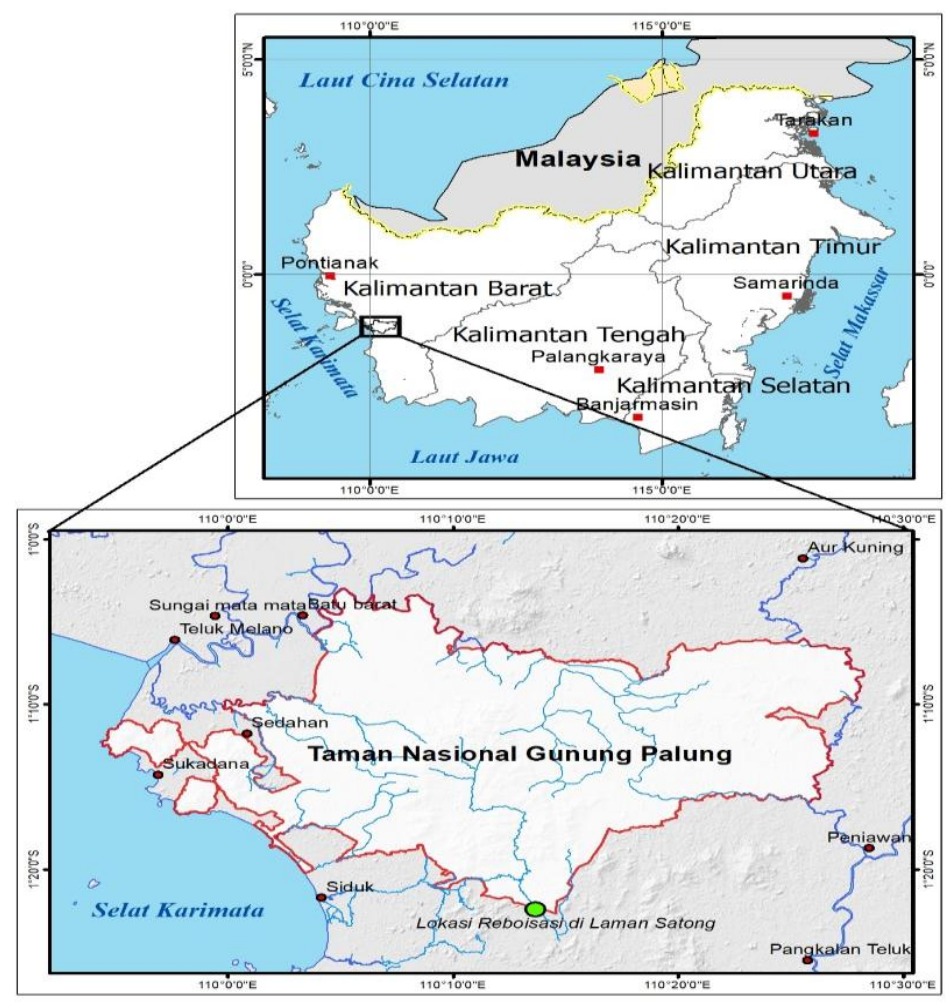

Gambar 1. Peta Lokasi Penelitian di Taman Nasional Gunung Palung dan Lokasi Reboisasi Untuk Pengamatan Biji. 


\section{B. Prosedur Penelitian dan Analisis}

Waktu penelitian dilakukan pada bulan Januari - Juni 2019. Untuk bulan Januari - Februari 2019 adalah waktu untuk mengumpulkan biji Shorea di hutan yang digunakan sebagai benih. Biji dari Marga Shorea yang dikumpulkan berasal di sekitar lokasi yang akan dilakukan reboisasi. Periode bulan Februari - Juni digunakan untuk mengukur tingkat perkecambahan dan tingkat pertumbuhan benih yang telah ditanam. Akhir tahun 2018 dan awal tahun 2019 merupakan musim berbuah massal yang terjadi di TNGP. Perbuahan massal tersebut berasosiasi dengan ENSO (El NiñoSouthern Oscillation) yang terjadi di tahun 2018 - 2019 (Becker, 2018; Curran and Leighton, 2000). Jenis biji yang melimpah dan yang dikumpulkan adalah jenis meranti merah (Shorea leprosula Miq.), tengkawang (Shorea macrophylla (de Vriese) P.S.Ashton), meranti putih (Shorea agami P.S.Ashton), dan belabak (Shorea quadrinervis Slooten).

Penggunaan jenis biji yang ditanam harus memiliki kesamaan kualitas. Biji yang dikumpulkan hanya biji yang jatuh dari pohon induk dan dalam kondisi yang bagus. Biji dalam kondisi utuh dan belum berkecambah atau telah menjadi anakan alami di hutan. Seleksi untuk biji yang sudah dikumpulkan dengan perendaman pada air. Biji yang tenggelam merupakan biji dengan kualitas baik. Untuk biji yang mengambang tidak diseleksi dan tidak ditanam. Sebanyak 38.728 biji lolos tahap seleksi ini. Biji yang telah diseleksi ditanam pada polybag ukuran tinggi $18 \mathrm{~cm}$ dan lebar $6 \mathrm{~cm}$. Tanah yang digunakan adalah tanam lapisan top soil hutan. Persemaian menggunakan jaring paranet $70 \%$ untuk memastikan benih yang ditanam tidak terpapar matahari langsung. Hal ini didasarkan naungan $60-70 \%$ adalah optimal untuk pertumbuhan (Setiawan et al., 2015).

Pengukuran daya hidup perkecambahan dilakukan setiap minggu selama satu bulan (4 minggu) sejak hari tanam (minggu 0). Daya hidup perkecambahan diukur dengan menghitung jumlah biji yang mati dalam polybag setiap minggu. Untuk menghitung daya hidup digunakan persentase jumlah benih yang hidup. Terdapat 10 plot penanaman yang terbagi atas waktu tanam dan jenis bibit (tabel 1). Tingkat pertumbuhan diukur 
setiap bulan setelah bulan ke satu hingga bulan ke empat. Parameter yang diukur adalah jumlah helai daun dan tinggi bibit dalam $\mathrm{cm}$.

\section{HASIL DAN PEMBAHASAN}

\section{A. Daya Hidup (survival rate) Biji}

Biji adalah bagian dari pohon yang ketika ditanam akan berkecambah dan tumbuh sesuai pohon asalnya. Daya hidup setiap bii berbeda beda sesuai tipe biji dan kondisi penanamannya. Untuk daya hidup benih marga Shorea pada penelitian ini berada diatas $80 \%$. Daya hidup biji paling tinggi dimiliki oleh belabak (Shorea quadrinervis) dengan rata-rata daya hidup sebesar $90,7 \%$. Daya hidup terendah untuk spesies S. quadrinervis adalah $71,8 \%$ dan tertinggi adalah 96,8\%. Meranti putih (Shorea agami) memiliki daya hidup biji sebesar 89,2\%. Tengkawang (Shorea macrophylla) memiliki daya hidup biji ratarata $89.25 \%$. Sedangkan yang paling rendah adalah meranti merah (Shorea leprosula) dengan rata-rata benih hidup selama 1 bulan adalah $82.9 \%$. Secara keseluruhan, untuk daya hidup benih marga Shorea di persemaian pada 10 blok dengan 38.728 benih ditanam adalah 92,7\%.

Tabel (Table) 1. Daya Hidup Biji Shorea Hasil Pengamatan Selama 1 Bulan (Survival rate of Shorea seed from one-month experiment)

\begin{tabular}{|c|c|c|c|c|c|c|c|c|c|}
\hline \multirow{3}{*}{ Blok } & \multirow{3}{*}{ Nama Lokal } & \multirow{3}{*}{ Nama Latin } & \multirow{3}{*}{ Tanam } & \multicolumn{5}{|c|}{ Survival rate benih (1 bulan) } & \multirow{3}{*}{$\%$} \\
\hline & & & & \multicolumn{5}{|c|}{ Minggu } & \\
\hline & & & & 0 & 1 & 2 & 3 & 4 & \\
\hline 1 & Meranti merah & Shorea leprosula & $23 / 01 / 2019$ & 724 & 694 & 662 & 631 & 598 & $82.6 \%$ \\
\hline 2 & Tengkawang & Shorea macrophylla & 28/01/2019 & 516 & 516 & 502 & 496 & 466 & $90.3 \%$ \\
\hline 3 & Tengkawang & Shorea macrophylla & $29 / 01 / 2019$ & 1,234 & 1,182 & 1,136 & 1,109 & 1,088 & $88.2 \%$ \\
\hline 4 & Meranti putih & Shorea agami & $29 / 01 / 2019$ & 2,428 & 2,338 & 2,354 & 2,322 & 2,294 & $94.5 \%$ \\
\hline 5 & Belabak & Shorea quadrinervis & 28/01/2019 & 1,546 & 1,546 & 1,520 & 1,490 & 1,426 & $92.2 \%$ \\
\hline 6 & Belabak & Shorea quadrinervis & $29 / 01 / 2019$ & 1,840 & 1,800 & 1,758 & 1,718 & 1,678 & $91.2 \%$ \\
\hline 7 & Belabak & Shorea quadrinervis & $01 / 02 / 2019$ & 8,086 & 8,036 & 7,976 & 7,907 & 7,829 & $96.8 \%$ \\
\hline 8 & Belabak & Shorea quadrinervis & $11 / 02 / 2019$ & 11,130 & 11,040 & 10,940 & 10,780 & 10,699 & $96.1 \%$ \\
\hline 9 & Belabak & Shorea quadrinervis & $18 / 02 / 2019$ & 8,728 & 8,528 & 8,351 & 8,177 & 8,020 & $91.9 \%$ \\
\hline \multirow[t]{3}{*}{10} & Belabak & Shorea quadrinervis & $20 / 02 / 2019$ & 2,496 & 2,270 & 2,077 & 1,917 & 1,793 & $71.8 \%$ \\
\hline & & Total Benih Hidup & & 38,728 & 37,950 & 37,276 & 36,547 & 35,891 & \\
\hline & & Persentase & & $100 \%$ & $98.0 \%$ & $96.3 \%$ & $94.4 \%$ & $92.7 \%$ & \\
\hline
\end{tabular}


Tingkat hidup pembenihan di persemaian lebih tinggi dari daya hidup di alam yang berkisar 7 - 28\% setelah satu tahun (Niiyama et al., 2016; Turner, 1990). Untuk jenis S. faguetiana memiliki daya hidup dipersemaian 89\% (Otsamo et al., 1996). S. macrophylla dilaporkan juga memiliki daya perkecambahan dalam rentang $70-85 \%$ (Hardjana and Rayan, 2011). S. leprosula juga memiliki rentang daya hidup antara 70 - 95\% (Cahyono and Rayan, 2012a). Jenis-jenis spesies dari marga Shorea memiliki tendensi daya hidup benih yang tinggi dibandingkan dengan spesies lainnya dalam suku dipterokarpa. Seperti Dipterocarpus grandifloras dan $D$. kunstleri memiliki daya hidup $7-25 \%$ di persemaian.

Terdapat beberapa hal yang mempengaruhi daya hidup perkecambahan biji dari marga Shorea ini. (1) Hal yang memungkinkan adalah kondisi biji yang kurang baik. Penelitian sebelumnya menemukan kualitas biji berkonstribusi besar terhadap rendahnya daya hidup biji yang ditanam. (2) Pergantian musim yang cepat tanpa diikuti oleh perawatan yang optimal. Biji yang ditanam jika terlalu banyak air akan busuk dan terlalu kering akan mati. (3) Musim berbuah yang terlewat akan menghasilkan biji yang membusuk atau telah menjadi anakan alami. Perlakukan terhadap anakan alami sudah tentu berbeda dengan perbiakan dari biji. (4) terdapat hama yang merusak perkecambahan.

\section{B. Pertumbuhan bibit}

Pertumbuhan bibit ditandai dengan jumlah helai daun dan tinggi dalam $\mathrm{cm}$. pertumbuhan helai daun menunjukkan bahwa tanaman telah mampu tumbuh dan berfotosintesis. Rata-rata pertumbuhan daun perbulan adalah 2 helai daun. Sedangkan untuk pertumbuhan tinggi, semakin lama bibit akan semakin cepat tinggi. Secara aritmatika, pertambahan tinggi perbulan adalah 5-10-15 cm dari bulan ke dua sampai ke empat. Dengan demikian, fase kritis dalam reproduksi Shorea adalah dalam satu bulan pertama. $S$. leprosula dan S. agami memiliki tingkat pertumbuhan yang lebih lambat jika dibandingkan $S$. macrophylla dan $S$. quadrinervis. Untuk jenis tengkawang, tinggi setelah 1 tahun mampu mencapai 1 meter (Cahyono and Rayan, 2012b). 
Tabel (Table) 1. Tingkat pertumbuhan marga Shorea dalam 4 bulan pengamatan (Growth rate of Shorea genus in four month experiment)

\begin{tabular}{clcccccccc}
\hline \multirow{2}{*}{$\begin{array}{c}\text { Blo } \\
\mathrm{k}\end{array}$} & \multirow{2}{*}{ Nama Latin } & \multicolumn{3}{c}{$\begin{array}{c}\text { Rata-rata pertmbuhan helai } \\
\text { daun per bulan (helai daun) }\end{array}$} & \multicolumn{4}{c}{$\begin{array}{c}\text { Rata-rata pertumbuhan tinggi } \\
\text { per bulan (cm) }\end{array}$} \\
\cline { 2 - 9 } & & B1 & B2 & B3 & B4 & B1 & B2 & B3 & B4 \\
\hline 1 & Shorea leprosula & 4 & 5 & 6 & 14 & 16 & 18 & 22 & 36 \\
2 & Shorea macrophylla & 3 & 4 & 5 & 7 & 12 & 20 & 28 & 48 \\
3 & Shorea macrophylla & 4 & 6 & 8 & 10 & 20 & 24 & 38 & 60 \\
4 & Shorea agami & 3 & 4 & 6 & 9 & 14 & 20 & 23 & 31 \\
5 & Shorea quadrinervis & 3 & 5 & 7 & 10 & 10 & 18 & 30 & 52 \\
6 & Shorea quadrinervis & 4 & 5 & 6 & 8 & 18 & 22 & 30 & 38 \\
7 & Shorea quadrinervis & 3 & 5 & 6 & 8 & 12 & 25 & 40 & 48 \\
8 & Shorea quadrinervis & 2 & 4 & 6 & 9 & 15 & 23 & 30 & 44 \\
9 & Shorea quadrinervis & 2 & 4 & 7 & 10 & 13 & 18 & 35 & 53 \\
10 & Shorea quadrinervis & 2 & 4 & 7 & 9 & 8 & 18 & 48 & 53 \\
\hline & & 3 & 5 & 6 & 9 & 14 & 21 & 32 & 46 \\
\hline
\end{tabular}

Hal yang perlu diperhatikan dalam perawatan bibit-bibit dipersemaian. (1) Penyiraman harus rutin dilakukan. Dalam rentang waktu $4-5$ bulan tersebut melewati musim kemarau yang kering. (2) Jika dimungkinkan penggunaan pupuk untuk mempercepat pertumbuhan bibit. Pupuk yang dapat digunakan yaitu pupuk akar atau pupuk NPK (Herdiana et al., 2008; Junaedi, 2012). Penyiraman yang teratur untuk menjaga kelembaban dan pemberian nutrisi tambahan melalui pupuk akan memberi percepatan pertumbuhan pada bibit agar segera siap tanam (Lavender, 1984).

Terkait teknis penanaman, setelah 10 tahun (2009 - 2019) Yayasan ASRI melakukan proyek reboisasi di kawasan
TNGP telah menghasilkan protokol untuk bibit yang akan ditanam. Bibit yang ditanam dalam proyek reboisasi harus memiliki tinggi minimal $40 \mathrm{~cm}$. Hal ini untuk membuat bibit yang ditanam mampu berkompetisi dengan gulma. Dari hasil penelitian ini, dari biji sampai siap tanam dibutuhkan waktu 4 - 5 bulan.

Penelitian ini hanya meneliti empat spesies dari marga Shorea. Untuk $S$. leprosula memiliki status ancaman dalam daftar merah IUCN dengan status konservasi hampir terancam (Pooma and Newman, 2017). Jadi populasinya di alam sudah menurun drastis namun masih berada ditahap mampu bertahan jika dilakukan upaya konservasi dan penghentian penebangan. Sedangkan untuk $S$. 
macrophylla sudah masuk dalam fase rentan untuk punah (Ashton, 1998a). Berbeda dengan $S$. agamii dan $S$. quadrinervis, kedua spesies ini telah masuk dalam klasifikasi genting dan butuh upaya konservasi (Ashton, 1998a, 1998b). Karena satu level lagi spesies ini akan berada pada ancaman status konservasi kritis yang sama dengan status konservasi orangutan.

\section{KESIMPULAN}

Daya benih dari biji untuk 4 spesies dari marga Shorea berada diatas $80 \%$. Daya hidup perkecambahan paling tinggi pada Shorea quadrinervis sebesar 98,7\%. Kami temukan bahwa pertumbuhan marga Shorea dari biji telah siap tanam dalam periode $4-5$ bulan. Hal ini mampu untuk menjadi suplai bibit yang berkualitas untuk program restorasi hutan di Indonesia.

\section{UCAPAN TERIMA KASIH}

Kami mengucapkan terima kasih kepada Balai Taman Nasional Gunung Palung yang telah membantu dalam proses pengumpulan biji di hutan. Ucapan terima kasih juga kepada masyarakat di Desa Laman Satong yang telah mendukung program reboisasi.

\section{DAFTAR PUSTAKA}

Ashton, P. (1998a). Shorea macrophylla. The IUCN Red List of Threatened Species 1998: e.T33620A9798047. Retrieved November 19, 2019, from http://dx.doi.org/10.2305/IUCN.UK.1 998.RLTS.T33620A9798047.en

Ashton, P. (1998b). Shorea quadrinervis. The IUCN Red List of Threatened Species 1998: e.T33695A9798202. Retrieved November 19, 1998, from http://dx.doi.org/10.2305/IUCN.UK.1 998.RLTS.T33695A9798202.en

Becker, E. (2018). September 2018 ENSO Update: back to school. Retrieved November 14, 2019, from https://www.climate.gov/newsfeatures/blogs/enso/september-2018enso-update-back-school

Cahyono, D. D. N., \& Rayan. (2012a). Perbandingan semai empat provenans Shorea Gysbertsiana BURCK di persemaian. Jurnal Penelitian Dipterokarpa, 6(1), 67-73. https://doi.org/10.20886/jped.2012.6. 1.67-73

Cahyono, D. D. N., \& Rayan. (2012b). Pertumbuhan semai Shorea leprosula Miq. dari berbagai pohon induk asal Kalimantan Barat di persemaian. Jurnal Penelitian Dipterokarpa, 6(1), 21-29.

Crowther, T. W., Glick, H., Maynard, D., Ashley-Cantello, W., Evans, T., \& Routh, D. (2017). Predicting Global Forest Reforestation Potential. BioRxiv, 210062. 
https://doi.org/10.1101/210062

Curran, L. M., \& Leighton, M. (2000). Vertebrate responses to spatiotemporal variation in seed production of mast-fruiting Dipterocarpaceae. Ecological Monographs, 70(1), 101-128. https://doi.org/10.1890/00129615(2000)070[0101:VRTSVI]2.0.C $\mathrm{O} ; 2$

Curran, L. M., Trigg, S. N., Mcdonald, a K., \& Astiani, D. (2004). Lowland Forest Loss in Protected Areas. Terra, 303(February), 1000-1003. https://doi.org/10.1126/science.10917 14

Elliott, S. D., Blakesley, D., \& Hardwick, K. (2013). Restoring tropical forests : a practical guide. Kew Publishing, Royal Botanic Gardens, Kew.

Fawzi, N. I., Indrayani, A. M., \& DeKay, K. (2019). Forest Change Monitoring and Environmental Impact in Gunung Palung National Park , West Kalimantan , Indonesia. Jurnal Ilmu Lingkungan, 17(2), 197-204. https://doi.org/10.14710/jil.17.2.197204

Gaveau, D. L. A., Locatelli, B., Salim, M. A., Yaen, H., Pacheco, P., \& Sheil, D. (2019). Rise and fall of forest loss and industrial plantations in Borneo (2000-2017). Conservation Letters, 12(3), $1-8$. https://doi.org/10.1111/conl.12622
Gaveau, D. L. A., Sloan, S., Molidena, E., Yaen, H., Sheil, D., Abram, N. K., ... Meijaard, E. (2014). Four decades of forest persistence, clearance and logging on Borneo. PLoS ONE, 9(7). https://doi.org/10.1371/journal.pone.0 101654

Hardjana, A. K., \& Rayan. (2011). Pertumbuhan bibit tengkawang (Shorea spp) asal biji dari populasi hutan alam Kalimantan di persemaian B2PD Samarinda. Jurnal Penelitian Dipterokarpa, 5(2), 61-72.

Helms, J. A., Woerner, C. R., Fawzi, N. I., MacDonald, A., Juliansyah, Pohnan, E., \& Webb, K. (2018). Rapid Response of Bird Communities to Small-Scale Reforestation in Indonesian Borneo. Tropical Conservation Science, 11, 1-8. https://doi.org/10.1177/19400829187 69460

Herdiana, N., Hakim, L. A., \& Mulyadi, K. (2008). Pengaruh dosis dan frekuensi aplikasi pemupukan NPK terhadap pertumbuhan bibit Shorea ovalis Korth. Jurnal Penelitian Hutan Dan Konservasi Alam, 5(3), 289-296. https://doi.org/10.20886/jphka.2008.5 .3.289-296

Junaedi, A. (2012). Pengaruh kompos dan pupuk NPK terhadap peningkatan kualitas bibit cabutan Shorea leprosula Miq. Jurnal Penelitian Hutan Dan Konservasi Alam, 9(4), 373-383.

https://doi.org/10.20886/jphka.2012.9 .4.373-383 
Lavender, D. P. (1984). Plant Physiology and Nursery Environment: Interactions Affecting Seedling Growth. In M. L. Duryea, T. D. Landis, \& C. R. Perry (Eds.), Forestry Nursery Manual: Production of Bareroot Seedlings (pp. 133-141).

https://doi.org/10.1007/978-94-0096110-4_14

Niiyama, K., Lida, S., Kimura, K., Sato, T., Azizi, R., \& Rahman, K. A. (2016). Survivorship of Shorea cutrisii seedlings in a hill dipterocarp forest, Peninsular Malaysia. Journal of Tropical Forest Science, 28, 334341.

Ode, M. D. L. (2012). Etnis Cina Indonesia dalam Politik: Politik Etnis Cina dan Singkawang di era Reformasi 19982008. Retrieved from https://books.google.co.id/books?id= S6fUCwAAQBAJ

Otsamo, R., Ådjers, G., Kuusipalo, J., Otsamo, A., Susilo, N., \& Tuomela, K. (1996). Effect of nursery practices on seed germination of selected dipterocarp species. Journal of Tropical Forest Science, 9(1), 23-34.

Pohnan, E., Ompusunggu, H., \& Webb, C. (2015). Does tree planting change minds? Assessing the use of community participation in reforestation to address illegal logging in West Kalimantan. Tropical Conservation Science, 8(1), 45-57. https://doi.org/10.1177/19400829150 0800107
Pooma, R., \& Newman, M. F. (2017). Shorea leprosula. The IUCN Red List of Threatened Species 2017: e.T33123A2833148. Retrieved November 19, 2019, from http://dx.doi.org/10.2305/IUCN.UK.2 017-3.RLTS.T33123A2833148.en

Salafsky, N. (1994). Forest gardens in the Gunung Palung region of West Kalimantan, Indonesia. Agroforestry Systems, 28(3), 237-268. https://doi.org/10.1007/BF00704759

Setiawan, A., Mardhiansyah, M., \& Sibudiani, E. (2015). Respon Pertumbuhan Semai Meranti Tembaha (Shorea leprosula Miq.) pada Medium Campuran Topsoil dan Kompos dengan Berbagai Tingkat Naungan. Jurnal Online Mahasiswa (JOM) Faperta, 2(2).

Sloan, S., Locatelli, B., Wooster, M. J., \& Gaveau, D. L. A. (2017). Fire activity in Borneo driven by industrial land conversion and drought during $\mathrm{El}$ Niño periods, 1982-2010. Global Environmental Change, 47, 95-109. https://doi.org/https://doi.org/10.1016 /j.gloenvcha.2017.10.001

Turner, I. M. (1990). The seedling survivorship and growth of three Shorea species in a Malaysian tropical rain forest. Journal of Tropical Ecology, 6, 469-478.

Wadley, R. L. (2006). Community Cooperatives, 'Illegal' Logging and Regional Autonomy in the Borderlands of West Kalimantan. In F. M. Cooke (Ed.), Asia-Pacific 
Environment Monograph 1: State,

Communities and Forests in

Contemporary Borneo (pp. 111-132).

Canberra, Australia: Australian

National University E Press.

Zamzani, F., Onda, N., Yoshino, K., \& Masuda, M. (2009). Deforestation and agricultural expansion processes in Gunung Palung National Park, West Kalimantan, Indonesia. Jurnal Manajemen Hutan Tropika, 15(1), 24-31. 